\title{
Comparative Study between Different Modulation Strategies for Five Levels NPC Topology Inverter
}

\author{
Noureddine Ould Cherchali ${ }^{1}$, Abdelhalim Tlemçani ${ }^{1}$, Mohemed Seghire Boucherit ${ }^{2}$, Linda Barazane ${ }^{3}$ \\ ${ }^{1}$ Laboratoire de Recherche en Electrotechnique et Automatique, Université de Médéa, Médéa, Alger \\ ${ }^{2}$ Laboratoire de Commande des Processus, Ecole Nationale Polytechnique, Algiers, Alger \\ ${ }^{3}$ Faculté d'Electronique, Université des Sciences et de la Technologie Houari Boumediene, Algiers, Alger \\ E-mail:nocherchali@yahoo.fr \\ Received April 29, 2011; revised May 15, 2011; accepted May 23, 2011
}

\begin{abstract}
The object of this paper is the study of various modulation strategies applied to the five-level inverter neutral-point-clamped NPC topology. Firstly we presented the structure of the voltage inverter three-phase five-level NPC topology. After that we model the inverter and the inverter are controlled by different strategies and then we made a comparative study between the results given by different strategies.
\end{abstract}

Keywords: Multilevel, Five Levels, NPC, SHEPWM, SPWM, Hysteresis Control

\section{Introduction}

In recent years, electrical industries have expanded and the variety of loads has increasingly grown. Recently, the industry has begun to apply high-voltage high-power equipment that has reached the megawatt range. Today, the direct connection of a single semiconductor switch to a system with medium sized voltage grids $(2.3,3.2,4.16$ and $6.9 \mathrm{KV}$ ) is too difficult. To overcome the limitations on semiconductor voltage and current ratings, some type of series connection will be necessary. Therefore, multilevel inverters have been introduced. Due to their ability to synthesize waveforms with a better harmonic spectrum and attain a higher voltage without transformers, they have been receiving increasing attention in the past few years.

There is several structure of multi levels inverter. in this work, we chose NPC topology [1] with five levels.

Today, there are many switching strategies which are applied to multilevel inverter topologies. The most known are [1]: the sinusoidal pulsewidth modulation SPWM strategy, the selective harmonic eliminated pulse width modulation method SHEPWM and hysteresis current control. These strategies modulations, which are very effective methods for controlling the multilevels inverters, will be presented here to control a three-phase voltage inverter five-level NPC topology [1-7].

In the first part, we will present the structure of the voltage inverter three-phase five-level NPC topology. Secondly, we will apply four strategies [1]:

- The sinusoidal pulse width modulation strategy with a one carrier;

- The four carriers sinusoidal pulse width modulation strategy;

- The selective harmonic eliminated pulse width modulation method SHEPWM strategy;

- The hysteresis current control.

In the third part we made a comparative study between these four strategies in several ways

\section{Modeling of Three-Phase Inverter a Five-Level NPC Topology}

The topology modeled in this study is the voltage inverter Three phase five-level topology NPC (Neutral Point Clamp) $[2,3]$.

Figure 1 shows the voltage three phase five-level NPC topology inverter. The symmetry of three-phase five-level inverters can model them by leg. So we begin by defining a global model of $q$ leg without a priori on the control (Figure 2).

A topological analysis of $q$ leg of the five-level inverter NPC topology shows seven configurations (Table 1 and Figure 3).

For a leg $k$, several complementary control laws are possible for the five-level NPC. The optimal control law of this inverter is: 


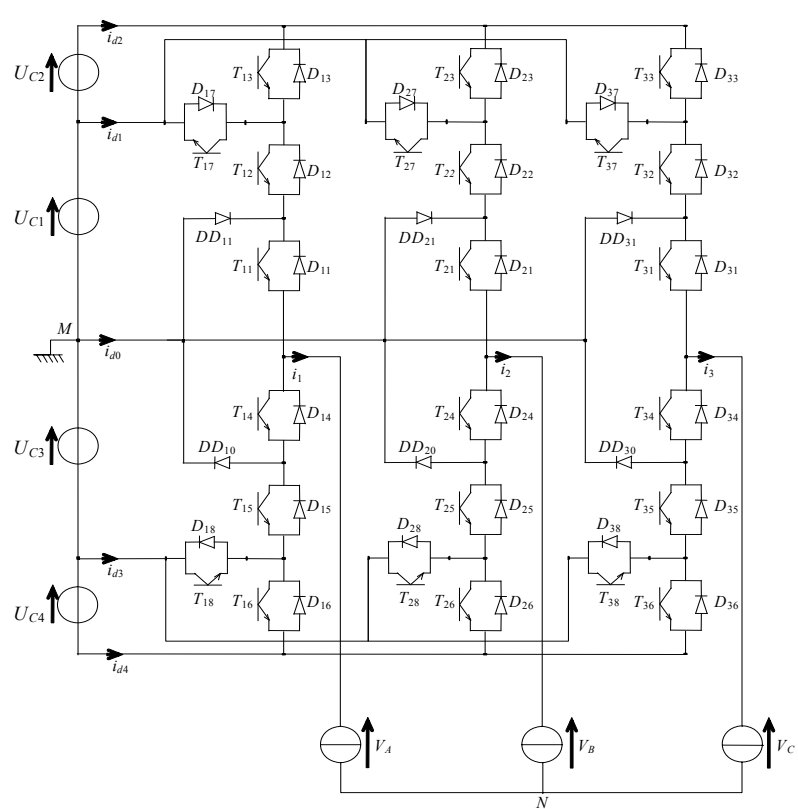

Figure 1. Three-phase inverter a five-level NPC topology.

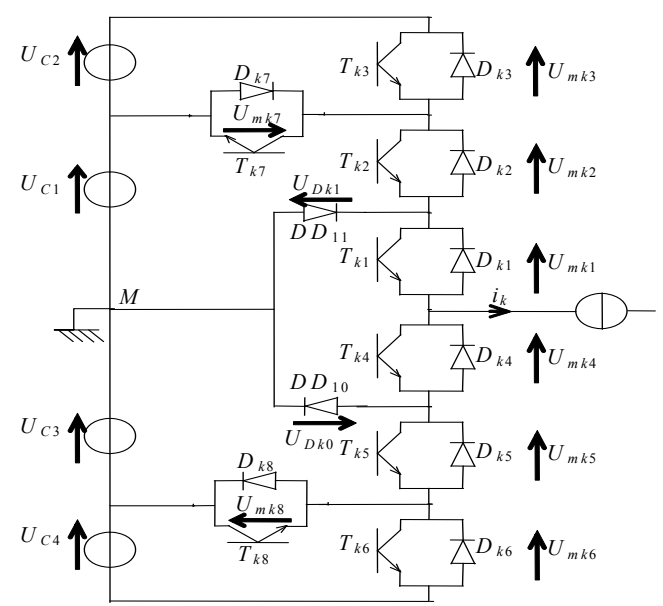

Figure 2. Leg of three-phase inverter a five-level NPC.

Table 1. Electrical quantities for each configuration of one leg $k$.

\begin{tabular}{cc}
\hline configuration & electrical quantities \\
\hline E0 & $I_{k}=0$ \\
E1 & $V_{k M}=U_{C 1}+U_{C 2}=2 U_{C}$ \\
E2 & $V_{k M}=U_{C 1}=U_{C}$ \\
E3 & $V_{k M}=0$ \\
E4 & $V_{k M}=-U_{C 3}=-U_{C}$ \\
E5 & $V_{k M}=-U_{C 3}-U_{C 4}=-2 U_{C}$ \\
E6 & $V_{k M}=0$ \\
\hline
\end{tabular}

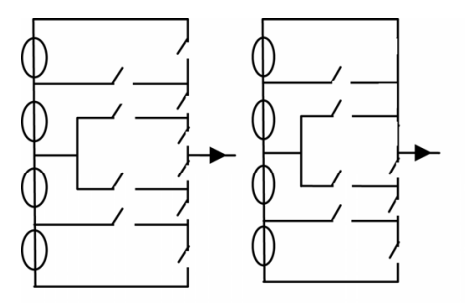

E1

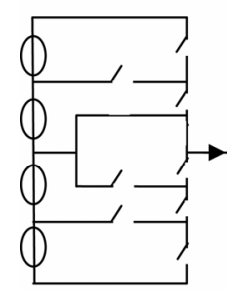

E3

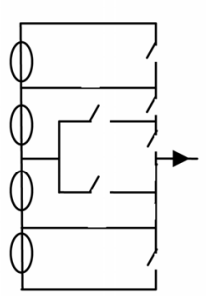

E4

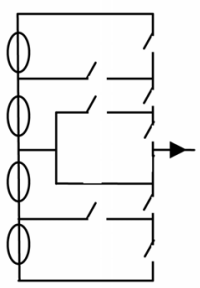

E6

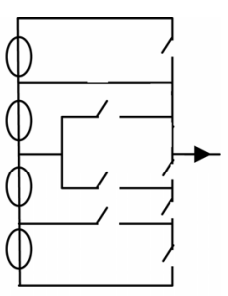

E2

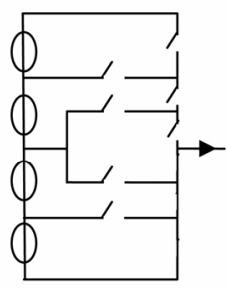

E5
Figure 3. The different configurations for $q$ leg $k$ of the inverter.

$$
\left\{\begin{array}{l}
F_{k 4}=1-F_{k 2} \\
F_{k 5}=1-F_{k 1} \\
F_{k 6}=1-F_{k 3}
\end{array}\right.
$$

for the leg $k$, We define a half leg connection function where $k=1,2,3$ : where $b=1$ refers to the lower half leg and $b=0$ to the upper half leg

$$
\left\{\begin{array}{l}
F_{k 1}^{b}=F_{k 1} F_{k 2} F_{k 3} \\
F_{k 0}^{b}=F_{k 4} F_{k 5} F_{k 6}
\end{array}\right.
$$

Connect functions for switches in parallel are defined as follows:

$$
\left\{\begin{array}{l}
F_{k 7}=F_{k 1} F_{k 2}\left(1-F_{k 3}\right) \\
F_{k 8}=F_{k 4} F_{k 5}\left(1-F_{k 6}\right)
\end{array}\right.
$$

The potentials of nodes A, B and C of Three phase five-level inverter relatively to the middle point $\mathrm{M}$ in the case $U_{C 1}=U_{C 2}=U_{C 3}=U_{C 4}=U_{C}$ are given by the following system:

$$
\left[\begin{array}{l}
V_{A M} \\
V_{B M} \\
V_{C M}
\end{array}\right]=\left[\begin{array}{l}
F_{17}+2 F_{11}^{b}-F_{18}-2 F_{10}^{b} \\
F_{27}+2 F_{21}^{b}-F_{28}-2 F_{20}^{b} \\
F_{37}+2 F_{31}^{b}-F_{38}-2 F_{30}^{b}
\end{array}\right] U_{C}
$$

The simple voltages at the boundaries of the load are given by the following system: 


$$
\left[\begin{array}{l}
V_{A} \\
V_{B} \\
V_{C}
\end{array}\right]=\frac{1}{3}\left[\begin{array}{ccc}
2 & -1 & -1 \\
-1 & 2 & -1 \\
-1 & -1 & 2
\end{array}\right]\left\{\left(\left[\begin{array}{l}
F_{17}+2 F_{11}^{b}-F_{18}-2 F_{10}^{b} \\
F_{27}+2 F_{21}^{b}-F_{28}-2 F_{20}^{b} \\
F_{37}+2 F_{31}^{b}-F_{38}-2 F_{30}^{b}
\end{array}\right] U_{C}\right.\right.
$$

\section{Control Strategies of the Five Levels Inverter}

\subsection{Sinusoidal Pulse Width Modulation Strategy with One Carrier}

The principle of this method $[3,8]$ is to impose on the machine terminals voltage pulses so that the fundamental tension is nearest the reference sinusoidal voltage. The moments of impulse control switches are determined by the intersection of the signal voltage reference called "modulator" with one triangular high frequency signal called a carrier. The characteristics of the method are:

Modulation index $m$ :

$$
m=\frac{f_{p}}{f}
$$

Modulation ratio $r$ :

$$
r=\frac{V_{m}}{2 U_{p m}} .
$$

Figure 4 shows the reference voltages and the carrier.

The algorithm of this strategy for arm $k$ of this inverter is that

$$
\begin{aligned}
& C 1:\left(0 \leq\left|V_{\text {refk }}\right| \leq U_{p m}\right) \&\left(\left|V_{\text {refk }}\right| \leq U_{p}\right) \\
& \Rightarrow F_{k 1}=1 ; F_{k 2}=0 ; F_{k 3}=0 \text {; } \\
& C 2:\left(0 \leq\left|V_{\text {refk }}\right| \leq U_{p m}\right) \&\left(\left|V_{\text {refk }}\right| \leq U_{p}\right) \&\left(V_{\text {refk }}>0\right) \\
& \Rightarrow F_{k 1}=1 ; F_{k 2}=1 ; F_{k 3}=0 \text {; } \\
& C 3:\left(0 \leq\left|V_{\text {refk }}\right| \leq U_{p m}\right) \&\left(\left|V_{\text {refk }}\right| \leq U_{p}\right) \&\left(V_{\text {refk }}<0\right) \\
& \Rightarrow F_{k 1}=0 ; F_{k 2}=0 ; F_{k 3}=1 \text {; } \\
& C 4:\left(U_{p m} \leq\left|V_{\text {refk }}\right| \leq 2 U_{p m}\right) \&\left(\left|V_{\text {refk }}^{\prime}\right| \leq U_{p}\right) \&\left(V_{\text {refk }}>0\right) \\
& \Rightarrow F_{k 1}=1 ; F_{k 2}=1 ; F_{k 3}=0 \text {; } \\
& C 5:\left(U_{p m} \leq\left|V_{\text {refk }}\right| \leq 2 U_{p m}\right) \&\left(\left|V_{\text {refk }}^{\prime}\right| \leq U_{p}\right) \&\left(V_{\text {refk }}<0\right) \\
& \Rightarrow F_{k 1}=1 ; F_{k 2}=1 ; F_{k 3}=0 \text {; } \\
& \text { C6: }\left(U_{p m} \leq\left|V_{\text {refk }}\right| \leq 2 U_{p m}\right) \&\left(\left|V_{\text {refk }}^{\prime}\right|>U_{p}\right) \&\left(V_{\text {refk }}>0\right) \\
& \Rightarrow F_{k 1}=1 ; F_{k 2}=1 ; F_{k 3}=1 \text {; } \\
& C 7:\left(U_{p m} \leq\left|V_{\text {refk }}\right| \leq 2 U_{p m}\right) \&\left(\left|V_{\text {refk }}^{\prime}\right|>U_{p}\right) \&\left(V_{\text {refk }}<0\right) \\
& \Rightarrow F_{k 1}=0 ; F_{k 2}=0 ; F_{k 3}=0 \text {; } \\
& \text { with } \quad V_{r e f k}^{\prime}=\left\{\begin{array}{lll}
V_{\text {refk }}-U_{p m} ; & \text { if } & V_{\text {refk }}>0 \\
V_{\text {refk }}+U_{p m} ; & \text { if } & V_{\text {refk }}<0
\end{array}\right.
\end{aligned}
$$

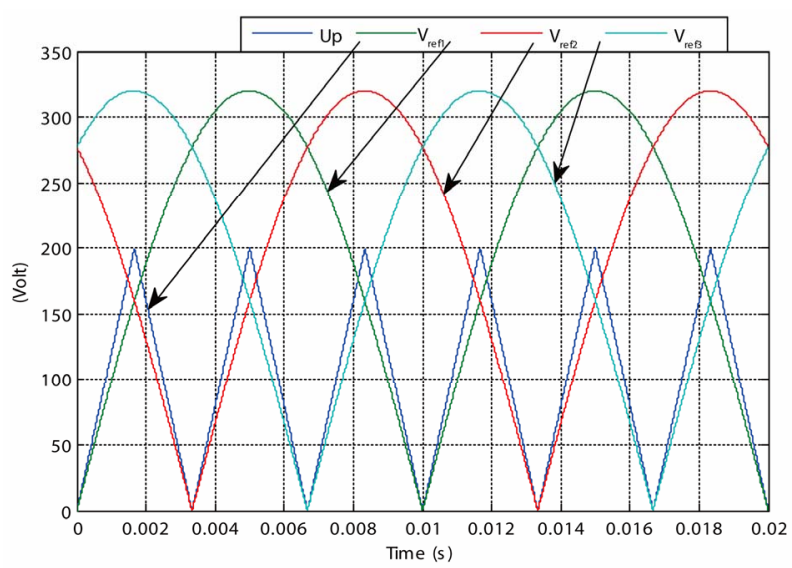

Figure 4. Different signals for the sinusoidal pulsewidth modulation strategy with a one carrier $(m=6, r=0.8)$.

Figures 5(a), 5(b) and 5(c) represent the voltage $V_{A}$ of a single inverter arm controlled by the sinusoidal pulse width modulation strategy with a one carrier

\subsection{The Four Carriers Sinusoidal Pulse Width Modulation Strategy}

In this section we will present the strategy sinusoidal pulse width modulation with four triangular bipolar carriers [3,9] (Figure 6). Where we use four triangular carriers bipolar $\left(U_{p 1}, U_{p 2}, U_{p 3}, U_{p 4}\right)$ dephased one quarter of the period $\left(T_{p} / 4\right)$ one relative to another. As SPWM strategy with a one carrier, this strategy is characterized by the modulation index $m$,

$$
m=\frac{f_{p m}}{f_{m}}
$$

and the modulation ratio $r$ :

$$
r=\frac{V_{m}}{U_{p m}}
$$

Algorithm of this strategy is as follows:

Step 1: determination of intermediate voltages $\left(V_{K 1}\right.$, $\left.V_{k 2}, V_{K 3}, V_{k 4}\right)$ :

$$
\begin{aligned}
& \left\{\begin{array}{l}
V_{\text {refk }} \geq U_{p 4} \Rightarrow V_{k 4}=2 U_{C} \\
V_{\text {refk }}<U_{p 4} \Rightarrow V_{k 4}=U_{C}
\end{array}\right. \\
& \left\{\begin{array}{l}
V_{\text {refk }} \geq U_{p 3} \Rightarrow V_{k 3}=U_{C} \\
V_{\text {refk }}<U_{p 3} \Rightarrow V_{k 3}=0
\end{array}\right. \\
& \left\{\begin{array}{l}
V_{\text {refk }} \geq U_{p 2} \Rightarrow V_{k 2}=0 \\
V_{\text {refk }}<U_{p 2} \Rightarrow V_{k 2}=-U_{C}
\end{array}\right. \\
& \left\{\begin{array}{l}
V_{\text {refk }} \geq U_{p 1} \Rightarrow V_{k 1}=U_{C} \\
V_{\text {refk }}<U_{p 1} \Rightarrow V_{k 1}=2 U_{C}
\end{array}\right.
\end{aligned}
$$



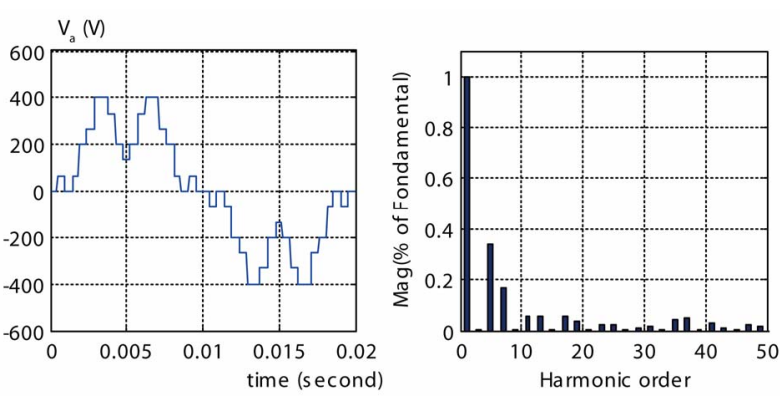

(a)
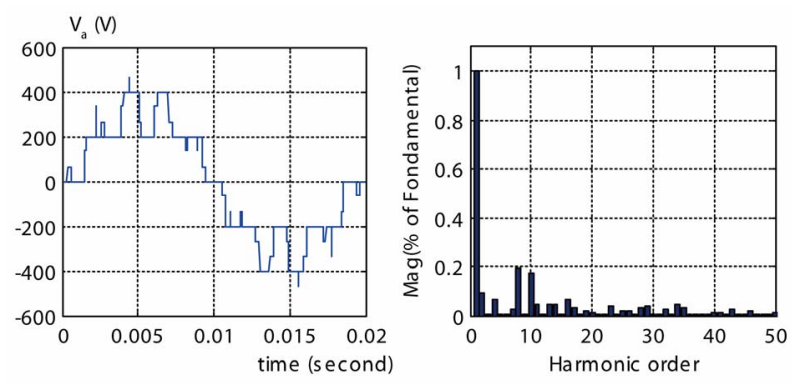

(b)
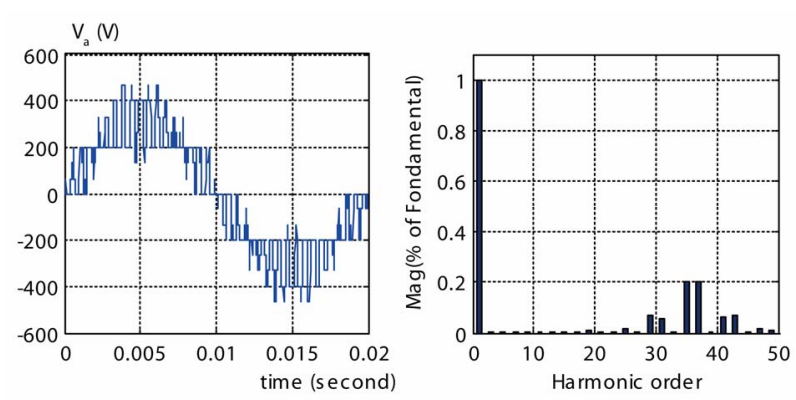

(c)

Figure 5. The simple voltage $V_{A}$ and its spectrum of Threephase five-level inverter controlled by The sinusoidal pulse width modulation strategy with a one carrier, (a) $m=6, r=$ 0.8 ; (b) $m=9, r=0.8$; (c) $m=36, r=0.8$.

Step 2: determination the signal $V_{k m}$ and control orders $B_{k s}$ switches

$$
V_{k m}=V_{k 1}+V_{k 2}+V_{k 3}+V_{k 4}
$$

$$
\begin{cases}V_{k m}=2 U_{C} & \Rightarrow F_{k 1}=1 ; F_{k 2}=1 ; F_{k 3}=1 \\ V_{k m}=U_{C} & \Rightarrow F_{k 1}=1 ; F_{k 2}=1 ; F_{k 3}=0 \\ V_{k m}=0 & \Rightarrow F_{k 1}=1 ; F_{k 2}=0 ; F_{k 3}=0 \\ V_{k m}=-U_{C} & \Rightarrow F_{k 1}=0 ; F_{k 2}=0 ; F_{k 3}=1 \\ V_{k m}=-2 U_{C} & \Rightarrow F_{k 1}=0 ; F_{k 2}=0 ; F_{k 3}=0\end{cases}
$$

Figures 7(a), 7(b) and 7(c) represent the output voltage $\mathrm{V}_{\mathrm{A}}$ and its spectrum of three-phase five-level inverter controlled by the strategy sinusoidal pulse width modulation with four triangular carriers

\subsection{The Selective Harmonic Eliminated Pulse Width Modulation SHEPWM Strategy}

The principle of control by elimination of harmonics [5,8-15] is to predetermine the moments of switching of Semiconductors in order to eliminate one harmonic or many harmonics of the desired row. To eliminate the harmonics of the following ranges: 5, 7, 11, 13 and 17, it will take 6 angles $\left(\alpha_{1}, \alpha_{2}, \alpha_{3}, \alpha_{4}, \alpha_{5}\right.$ and $\left.\alpha_{6}\right)$ (Figure 8).

After analyzing the Fourier series will be a system of nonlinear Equations (13). We must solve this system by a numerical method (Newton-Rafson $[10,11]$ or Genetic Algorithms [12-15].

$U_{c}$ : supply voltage.

$\alpha_{i}$ : switching angles.

The required solution must satisfy the following condition

$$
0<\alpha_{1}<\alpha_{2}<\alpha_{3}<\alpha_{4}<\alpha_{5}<\alpha_{6}<\pi / 2
$$

As mentioned, the system equations are nonlinear. In order to solve these equations the genetic algorithm (GA), which is based on natural evolution and populations, is implemented. This algorithm is usually used to reach a near global solution. In each iteration of the GA a new set of trings, which are called chromosomes, with improved fitness produced using genetic operators.

A more complete discussion of GAs including ex- tensions o the general algorithm and related topics can be found in books by Davis [16], Goldberg [17], Holland [18], and Deb [19].

$$
\left\{\begin{array}{l}
\cos \left(\alpha_{1}\right)-\cos \left(\alpha_{2}\right)+\cos \left(\alpha_{3}\right)+\cos \left(\alpha_{4}\right)-\cos \left(\alpha_{5}\right)+\cos \left(\alpha_{6}\right)=\frac{\pi}{4 U_{C}} r \\
\cos \left(5 \alpha_{1}\right)-\cos \left(5 \alpha_{2}\right)+\cos \left(5 \alpha_{3}\right)+\cos \left(5 \alpha_{4}\right)-\cos \left(5 \alpha_{5}\right)+\cos \left(5 \alpha_{6}\right)=0 \\
\cos \left(7 \alpha_{1}\right)-\cos \left(7 \alpha_{2}\right)+\cos \left(7 \alpha_{3}\right)+\cos \left(7 \alpha_{4}\right)-\cos \left(7 \alpha_{5}\right)+\cos \left(7 \alpha_{6}\right)=0 \\
\cos \left(11 \alpha_{1}\right)-\cos \left(11 \alpha_{2}\right)+\cos \left(11 \alpha_{3}\right)+\cos \left(11 \alpha_{4}\right)-\cos \left(11 \alpha_{5}\right)+\cos \left(11 \alpha_{6}\right)=0 \\
\cos \left(13 \alpha_{1}\right)-\cos \left(13 \alpha_{2}\right)+\cos \left(13 \alpha_{3}\right)+\cos \left(13 \alpha_{4}\right)-\cos \left(13 \alpha_{5}\right)+\cos \left(13 \alpha_{6}\right)=0 \\
\cos \left(17 \alpha_{1}\right)-\cos \left(17 \alpha_{2}\right)+\cos \left(17 \alpha_{3}\right)+\cos \left(17 \alpha_{4}\right)-\cos \left(17 \alpha_{5}\right)+\cos \left(17 \alpha_{6}\right)=0
\end{array}\right.
$$




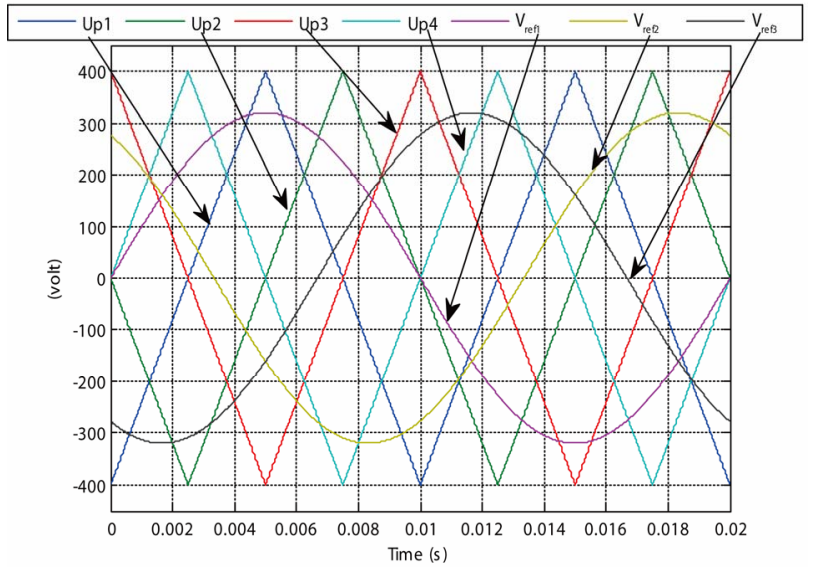

Figure 6. Different signals for the four carriers sinusoidal pulsewidth modulation strategy $(m=6, r=0.8)$.

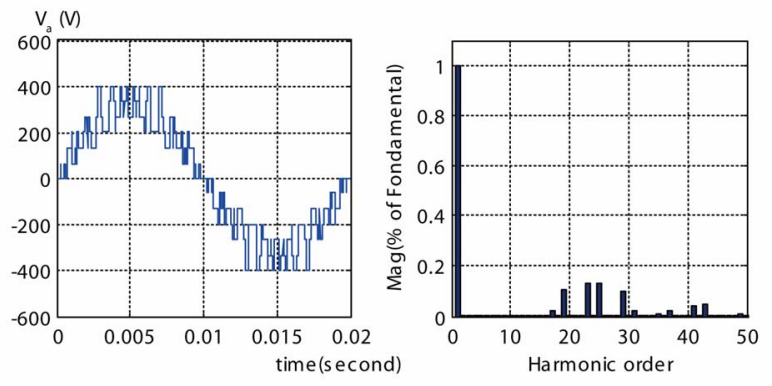

(a)
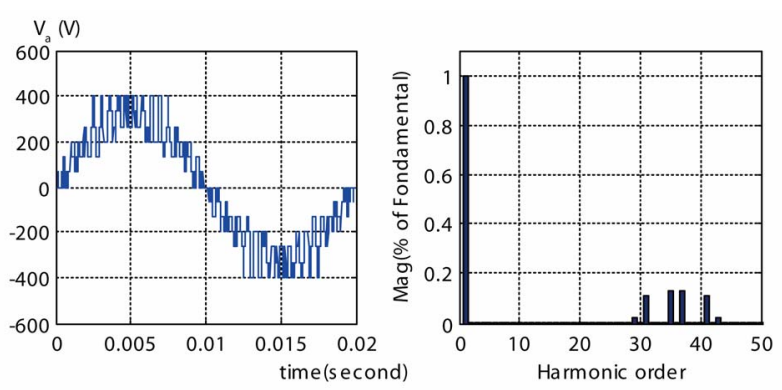

(b)
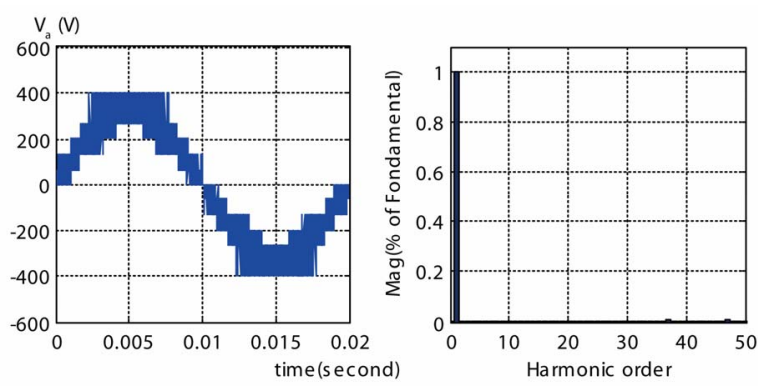

(c)

Figure 7. The simple voltage $V_{A}$ and its spectrum of Threephase five-level inverter controlled by the four carriers sinusoidal pulse width modulation strategy; (a) $m=6, r=$ 0.8 ; (b) $m=9, r=0.8$; (c) $m=36, r=0.8$.

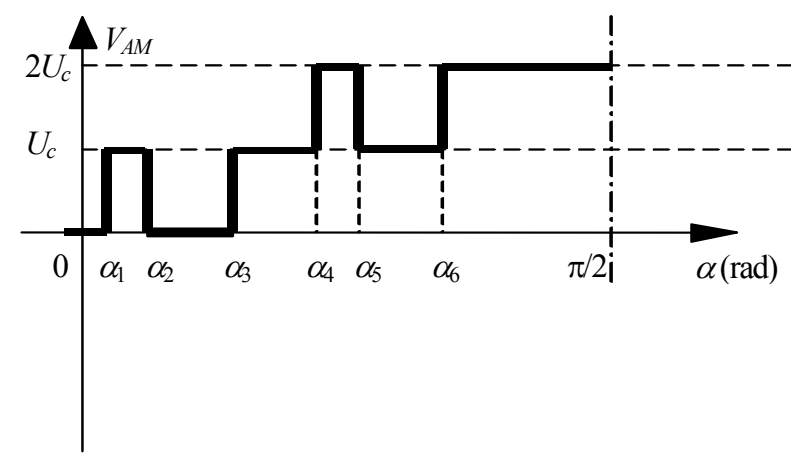

Figure 8. The waveform of the first quarter of tension $V_{A M}$.

The structure of a simple GA consists mainly of three operators: a selection operator, a crossover operator which acts on a population of strings to perform the required reproduction and recombination, and a mutation operator which randomly alters character values, usually with a very low probability. The effect of these random alterations is to maintain diversity within the population, thereby preventing an early convergence of the algorithm to a possibly false peak.

Figure 9 represents the flowchart of Genetic Algorithm [12].

Figure 10 represents the values of the six switching angles obtained after the resolution of the system (13) as function of $r$.

Figures 11(a)-(c) represent the single voltage $V_{A}$ and its spectrum of an inverter arm controlled by the SHEPWM strategy.

\subsection{The Hysteresis Current Control}

The principle this method [20-23] is based on determination the switching angles of switches so that the variation of current in each phase follows a sinusoidal current reference with a range of error $\Delta i$ where the current slide into a sliding surface.

If one considers $\varepsilon \mathrm{k}$ the difference between the real current ik and reference current $i_{\text {refk }}$. $\left(\varepsilon_{k}=i_{k}-i_{\text {refk }}\right.$ with $k$ $=1.2$ and 3 ).

The switches control commands $B_{k s}$ for the arm $k$ are given by the following algorithm

$$
\left\{\begin{array}{l}
C 1: \varepsilon_{k}<2 \Delta_{i} \Rightarrow F_{k 1}=0 ; F_{k 2}=0 ; F_{k 3}=0 ; \\
C 2: \Delta_{i}<\varepsilon_{k}<2 \Delta_{i} \Rightarrow F_{k 1}=0 ; F_{k 2}=0 ; F_{k 3}=1 ; \\
C 3:-2 \Delta_{i}<\varepsilon_{k}<-\Delta_{i} \Rightarrow F_{k 1}=1 ; F_{k 2}=1 ; F_{k 3}=0 ; \\
C 4 ; \varepsilon_{k}<-2 \Delta_{i} \Rightarrow F_{k 1}=1 ; F_{k 2}=1 ; F_{k 3}=1 ; \\
\text { if not the command doe no change }
\end{array}\right.
$$

Figure 12 and Figure 13 show respectively the reference and real currents with the difference between them two, the output voltage of the inverter and the harmonic 


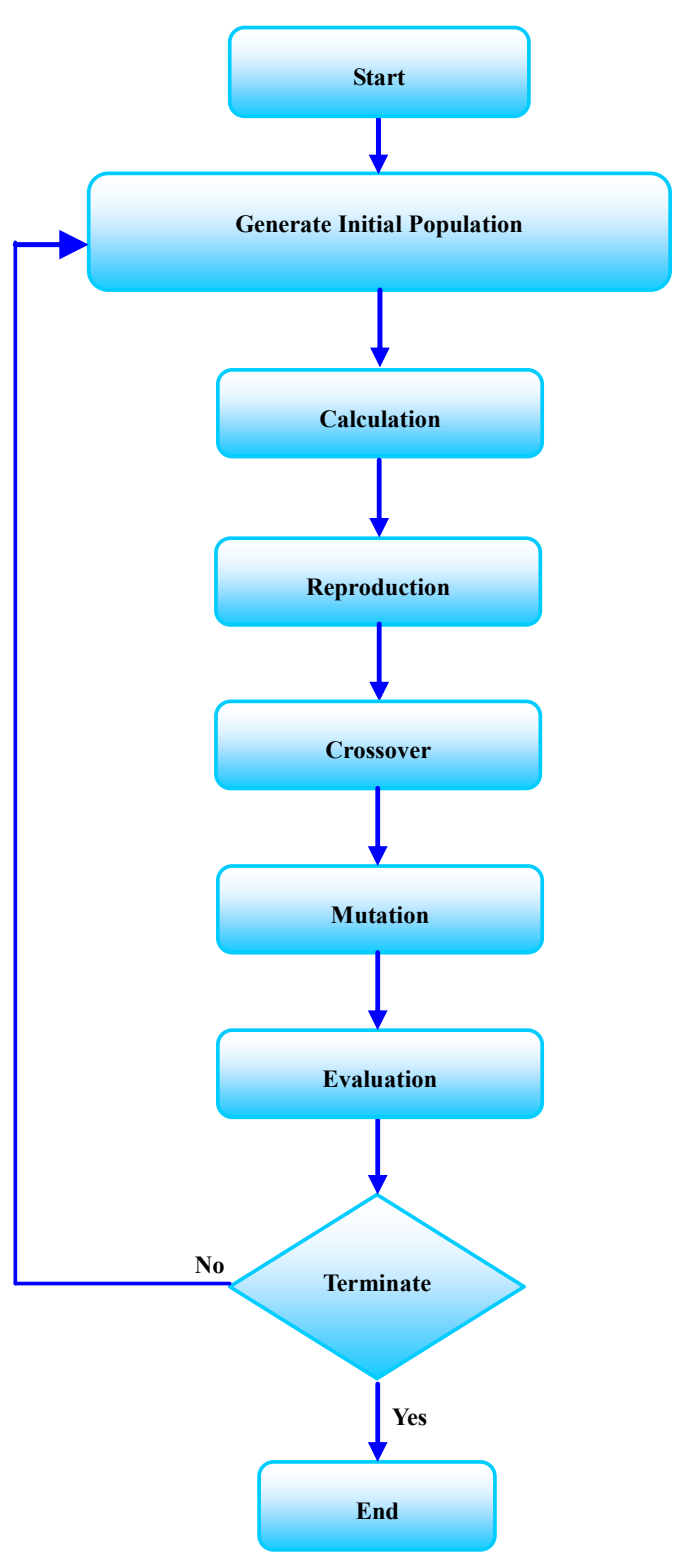

Figure 9. Flowchart of genetic algorithm.

$\Delta i=0.5 \mathrm{~A}$ and $\Delta i=0.1 \mathrm{~A}$.

\section{Comparative Study}

The comparative study between the different strategies for controlling the inverter three-phase five-level NPC structure is performed to:

*The same frequency of output voltage $(f=50 \mathrm{~Hz})$

*The same the modulation ratio $(r=0.8)$ for both strategies sinusoidal pulse width modulation strategy with a one carrier and four carriers.

According to Figures 5 and 7, we note that the increasing of the modulation index $\mathrm{m}$ can be pushed the harmonics to the higher frequencies and therefore can

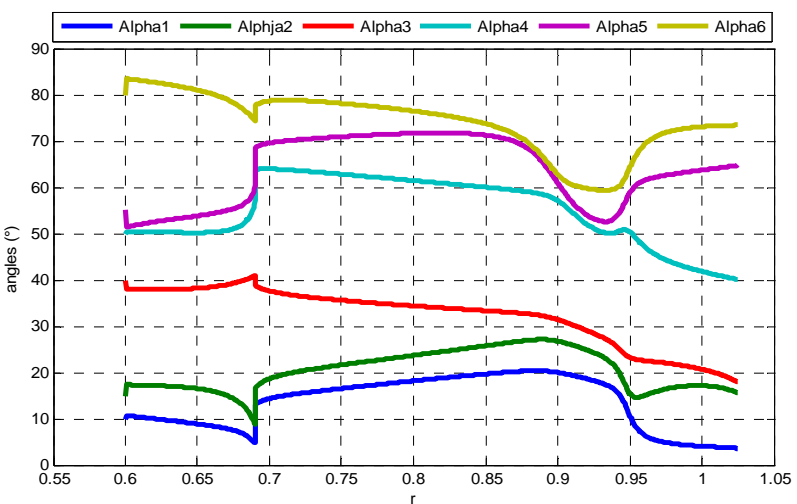

Figure 10. Six switching angles as function of modulation rate $\mathbf{r}$, for the SHEPWM strategy to eliminate 5 harmonics $(5,7,11,13$ and 15$)$.
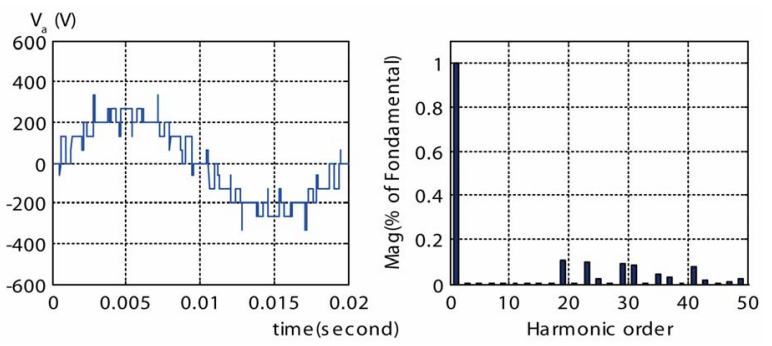

(a)
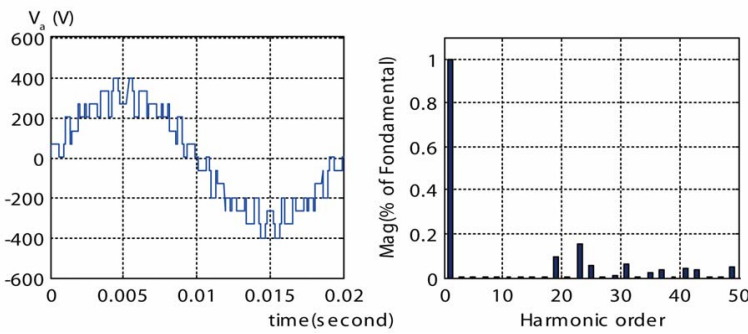

(b)
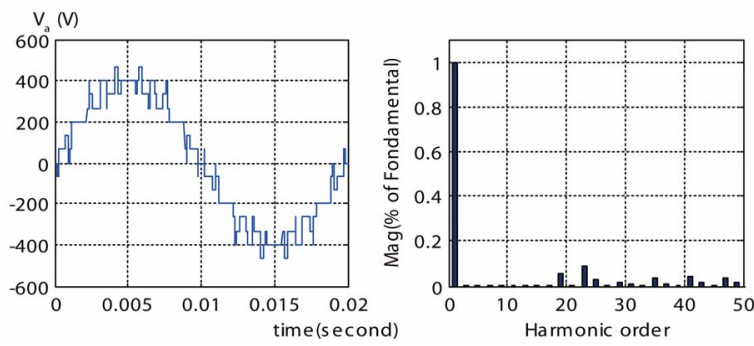

(c)

Figure 11. The simple voltage $V_{A}$ and its spectrum of threephase five-level inverter controlled by for SHEPWM strategy to eliminate 5 harmonics $(5,7,11,13$ and 17). (a) $r$ $=0.6$; (b) $r=0.8$; (c) $r=1$.

easily be filtered. For The sinusoidal pulse width modulation strategy with a one carrier, we have for $m$ even only the odd harmonics exist, for $m$ odd, we have odd 

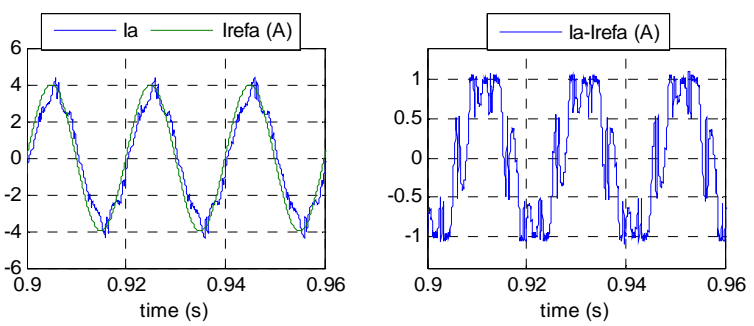

(a)
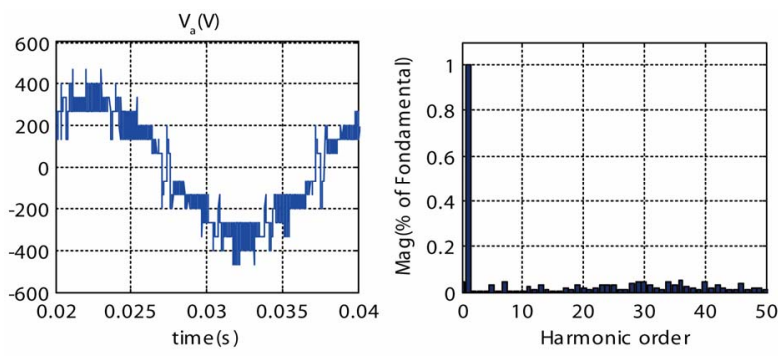

(b)

Figure 12. (a) reference and real currents and the difference between the two currents $\varepsilon_{A}$; (b) The simple voltage $V_{A}$ and its spectrum of three-phase five-level inverter controlled by the hysteresis current control $(\Delta i=0.5 \mathrm{~A})$.
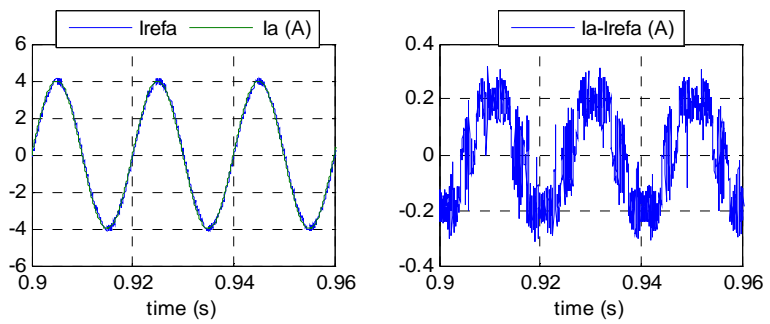

(a)
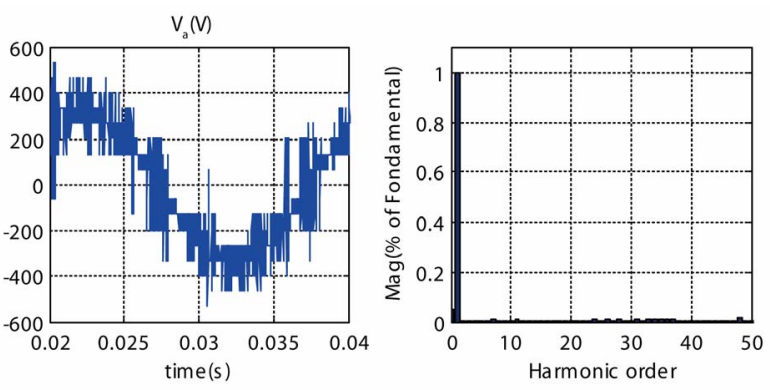

(b)

Figure 13. (a) reference and real currents and the difference between the two currents $\varepsilon_{A}$; (b) The simple voltage $V_{A}$ and its spectrum of three-phase five-level inverter controlled byThe hysteresis current $\operatorname{control}(\Delta i=0.1 \mathrm{~A})$.

harmonics and even harmonics too. For the strategy sinusoidal pulse width modulation four carriers it has only even harmonics.

Figure 11 shows the existence of only odd harmonics and the magnitudes of first eliminated har- monics are null.

We note for the hysteresis current control is characterized by hysteresis band $\Delta i$. From Figures 12 and $\mathbf{1 3}$ it is observed that the hysteresis current control is characterized by a variable frequency modulation. This change will be even higher than the hysteresis value of $(\Delta i)$ will be low. The spectrum of the voltage VA, has even and odd harmonics, the magnitudes of harmonic nearly negligible compared to that of the fundamental especially for $\Delta i=0.1$.

Figures 14 show the total harmonic distortion THD of the voltage $V_{A}$, and the magnitude of the fundamental harmonic.

The characteristic of adjustment strategy for the sinusoidal pulse width modulation strategy with a one carrier is linear for $r=0$ to 0.5 , and 0.56 to 1 but for $r=$ 0.5 to 0.56 it's constant because of the condition (16). And total harmonic distortion is decreasing function of $r$ (Figure 13(a)).

$$
U_{p m} \leq\left|V_{\text {refk }}\right| \leq 2 U_{p m}
$$

For The four carriers sinusoidal pulse width modution strategy the modulation ratio $r$ are like for the strategy with a one carrier, we have a linear adjustment of the magnitude of the fundamental $r=0$ to 1 . The total harmonic distortion THD decreases when $r$ increases (Figure 14(b)), this strategy is better than with a one carrier.

The modulation ratio $r$ of the SHEPWM strategy is linear from 0.6 to $r=1.02$ (Figure 14(c)) beyond this interval the system of nonlinear equation has no solutions after condition of angles (14). We note that the THD decreases as $r$ increases. And we see also the best value for $\mathrm{r}$ which gives a low total harmonic distortion is 0.9 and $r=1.00$

About The hysteresis current control, it is usefully than other strategies, more it can be controlled in closed loop, but we have to make an optimal control for low values of range $(\Delta I)$. And the output voltages are asynchronous and no periodical.

\section{Conclusions}

In our work we presented and modeled the three-phase five-level inverter NPC structure then we applied to it different strategies: The sinusoidal pulse width modulation strategy with a one carrier, The four carriers sinusoidal pulse width modulation strategy, the selective harmonic eliminated pulse width modulation method SHEPWM strategy and at the end we saw The hysteresis current control.

After this study, we can note the following: 


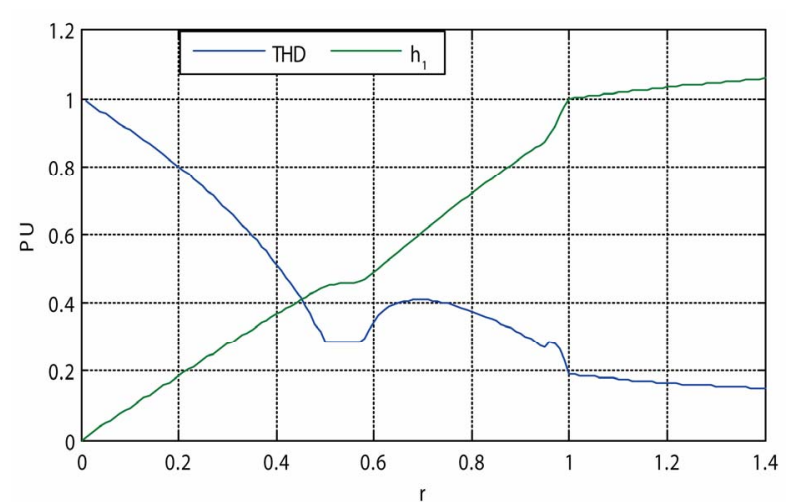

(a)

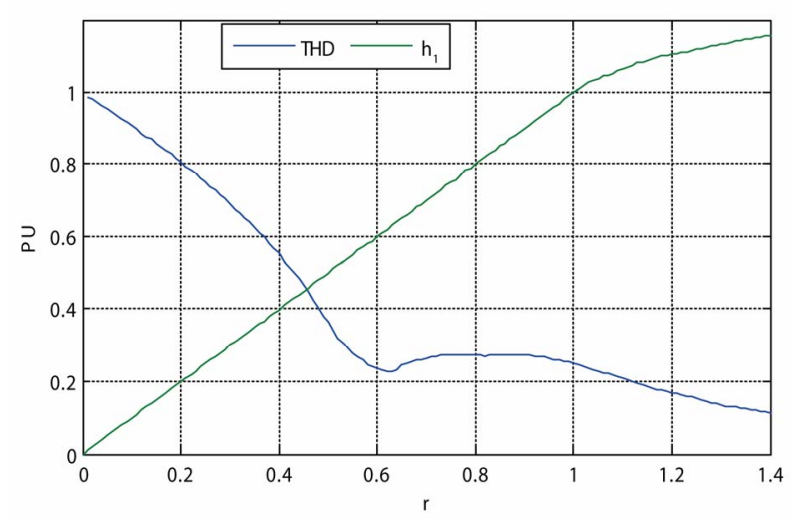

(b)

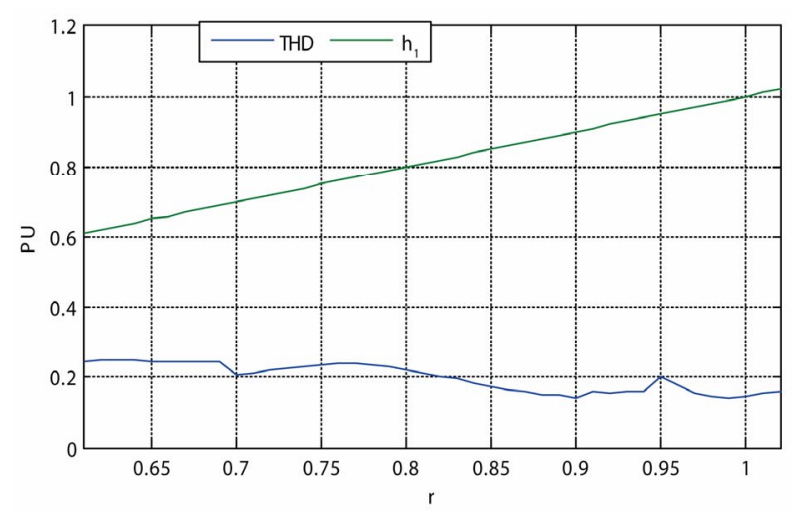

(c)

Figure 14. THD results and fundamental harmonic; (a) The strategy with a one carrier $(m=6)$; (b) The four carriers sinusoidal pulsewidth modulation strategy $(m=6)$; (c) The SHEPWM strategy to eliminate 5 harmonics $(5,7,11,13$ and 17).

The four carriers sinusoidal pulse width modulation strategy is more favorable than the sinusoidal pulse width modulation strategy with a one carrier, and it can be made with analog circuits.

Selective harmonic eliminated pulse width modulation method SHEPWM strategy is favorable to other control strategies in terms of number of switching (commutation energy dissipation) and noise nuisance.

The hysteresis current control it perfectly follows the current reference, it can be controlled in closed loop.

\section{References}

[1] B. S. Suh, G. Sinha, M. D. Manjrekar and T. A. Lipo, "Multilevel Power Conversion-An Overview of Topologies and Modulation Strategies," IEEEOPTIM Conference Record, Vol. 2, 1998, pp. 11-24.

[2] R. Guedouani, B. Fiala, E. M. Berkouk and M. S. Boucherit, "Control of Capacitor Voltage of Three Phase Five-Level NPC Voltage Source Inverter. Application to Inductor Motor Drive," International Aegean Conference on Electrical Machines and Power Electronics, Bodrum, 10-12 September 2007, pp. 794-799. doi:10.1109/ACEMP.2007.4510609

[3] R. Guedouani, B. Fiala, E. M. Berkouk and M. S. Boucherit, "Modelling and Control of Three-Phase PWM Voltage Source Rectifiers-Five-Level NPC Voltage Source Inverter-Induction Machine System," 18th Mediterranean Conference on Control \& Automation, Marrakech, 23-25 June 2010, pp. 533-538,

[4] F. Bouchafaa, D. Beriber, M. S. Boucherit and E. M. Berkouk, "Enslavement and Control of the Multi DC-Bus Link Voltages Using Adaptive Fuzzy," 8th International Symposium on Advanced Electromechanical Motion Systems \& Electric Drives Joint Symposium, Lille, 1-3 July 2009, pp. 1-7.

doi:10.1109/ELECTROMOTION.2009.5259075

[5] S. R. Pulikanti and V. G. Agelidis, "Five-Level Active NPC Converter Topology: SHE-PWM Control and Operation Principles," Australasian Universities Power Engineering Conference, Perth, 9-12 December 2007, pp. 1-5. doi:10.1109/AUPEC.2007.4548071

[6] R. Chibani, E. M. Berkouk and M. S. Boucherit, "FiveLevel NPC VSI: Different Ways to Balance Input DC Link Voltages," ELEKTRIKA Journal, Vol. 11, No. 1, 2009, pp. 19-33.

[7] A. Nabae, I. Takahashi and H. Akagi, "A New Neutral-Point-Clamped PWM Inverter," IEEE Transactions on Industrial Applications, Vol. 17, No. 5, 1981, pp. 518-523. doi:10.1109/TIA.1981.4503992

[8] S. A. Mohamed, M. Dahidah and G. Vassilios Agelidis "Single-Carrier Sinusoidal PWM-Equivalent Selective Harmonic Elimination for a Five-Level Voltage Source Converter," Electric Power Systems Research, Vol. 78, No. 11, 2008, pp. 1826-1836. doi:10.1016/j.epsr.2008.01.021

[9] P. K. Chaturvedi, J. Shailendra and P. Agrawal, "A Study of Neutral Point Potential and Common Mode Voltage Control in Multilevel SPWM Technique," Proceedings of the 15th National Systems Conference, Bombay, 16-18 December 2008, pp. 518-523.

[10] N. Ould Cherchali, N. Henini, S. Boulkhrachef, L. Barazane and M. S. Boucherit, "Contribution of SHEPWM 
Strategy in the Control of NPC Five Levels Inverter, Application to Induction Machine," Control 2nd International Conference on Electrical and Electronics Engineering, Laghouat, 21-23 April 2008, pp. 461-466.

[11] S. Sirisukprasert, "Optimized Harmonic Stepped-Waveform for Multilevel Inverter," Master's Thesis, Department of Electrical and Computer Engineering, Virginia Polytechnic Institute and State University, Blacksburg, 1999.

[12] N. Ould Cherchali, B. Bentchikou, A. Tlemçani, L. Barazane and M. S. Boucherit, "Contribution dans l'Application des Algorithmes Génétiques pour Commander des Onduleurs de Tension à Cinq Niveaux par la Technique d'Elimination d'Harmoniques," 3rd Conference on Electrical Engineering, Algiers, 19-21 May 2009.

[13] S. A. Mohamed, M. Dahidah and V. C. Rao, "A Hybrid Genetic Algorithm for Selective Harmonic Elimination PWM AC/AC Converter," Control Electrical Engineering, Vol. 89, No. 4, 2007, pp. 285-291. doi:10.1007/s00202-006-0003-9

[14] X. Zhou and W. Liu, "Novel Technique of Selected Harmonic Elimination Pulse Width Modulation Based on Space Voltage Vectors," Proceeding of the CSEE 2009, Vol. 29, No. 30, 2009, pp. 35-41.

[15] M. G. Hosseini Aghdam, S. H. Fathi and G. B. Gharehpetian, "A Complete Solution of Harmonics Elimination Problem in a Multi-level Inverter with Unequal DC Sources," Journal of Electrical Systems, Vol. 3, No. 4, 2007, pp. 259-271.
[16] L. D. Davis, "The Handbook of Genetic Algrithms," Van Nostrand Reinhold, New York, 1991.

[17] D. E. Goldberg, "Genetic Algorithms in Search, Optimization, and Machine Learning," Addison Wesley, Boston, 1989.

[18] J. H. Holland, "Adaptation in Natural and Artificial Systems," The University of Michigan Press, Ann Arbor, 1975.

[19] K. Deb, "Multi-objective Optimization Using Evolutionary Algorithms," John Wiley \& Sons, Hoboken, 2001.

[20] G. H. Bode, P.-C. Tan and P. C. Loh, "Modular Hysteresis Current Control of Hybrid Multilevel Inverters," IEE Proceedings of Electric Power Applications, Vol. 152, No. 1, 2005, pp. 1-8. doi:10.1049/ip-epa:20041219

[21] K. A. Corzine, "A Hysteresis Current-Regulated Control for Multi-Level Drives," IEEE Transactions on Energy Conversion, Vol. 15, No. 2, 2000, pp. 169-175. doi: $10.1109 / 60.866995$

[22] L. Dalessandro, S. D. Round and J. W. Kolar, "Center-Point Voltage Balancing of Hysteresis Current Controlled Three-Level PWM Rectifiers," IEEE Transactions on Power Electronics, Vol. 23 , No. 5, 2008, pp. 2477 2488. doi:10.1109/TPEL.2008.2002060

[23] B.-J. Kang and C.-M. Liaw, "A Robust Hysteresis Current-Controlled PWM Inverter for Linear PMSM Driven Magnetic Suspended Positioning System," IEEE Transactions on Industrial Electronics, Vol. 48, No. 5, 2001, pp. 956-967. doi: 10.1109/41.954560 